\title{
Metal-free organic dyes derived from phenothiazine for dye sensitized solar cells; tuning of the performances by imidazole derivative
}

\begin{abstract}
Three imidazole - triphenylamine based organic dyes (SS PI1, SS PI2 and SS PI3) configured with donor - donor $-\pi$ spacer - acceptor (D-D- $\pi$-A) structures were synthesized with different acceptor units. The optical and electrochemical performances of the dyes were analyzed carefully. Based on the analysis on the performance of the synthezied dyes towards the application of DSC are which has been suggested as an accountable for greater DSC's efficiency. So, this new molecular design could trigger the future development of other simple organic photosensitizers for efficient DSC's which support the sustainability of the modern society.
\end{abstract}

Keywords: dyes sensitized solar cells, phenothiazine, acceptor, efficiency, sustainability
Volume 2 Issue 3 - 2018

\author{
Sambathkumar S, ${ }^{1,2}$ Priyadharshini $S,{ }^{2}$ Saritha \\ $A,{ }^{\prime}$ Renganathan $\mathrm{R}^{2}$ \\ 'Department of Chemistry, Theivanai Ammal College for \\ Women (Autonomous), India

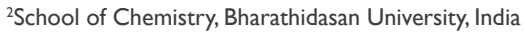
Correspondence: Sambathkumar Subramaniyan, Department of Chemistry, Theivanai Ammal College for Women
(Autonomous), Villupuram 605 40I, India Tel +91999913 4304, Email sambathkumarraj@gmail.com

Received: December 13,2017 | Published: May 18, 2018

\section{Introduction}

Exclusively organic dyes continue to capture the attention of scientific community devoted to the development of dye sensitized solar cells as a competitive alternative to ruthenium based complexes. ${ }^{1}$ Many organic dyes based on the push-pull structure of donor conjugated linker-acceptor system, which exhibit relatively high DSC performances have already been designed and developed. ${ }^{2-5}$ Organic dyes can be divided into two categories, one containing triarylamine donors while the others have heterocyclic donors. The electron rich nature of phenothiazine moiety provides a good relay for the electron migration from donor to acceptor, which can induce an efficient intramolecular charge transfer (ICT). Phenothiazine has electron rich sulfur and nitrogen heteroatom, and its ring is non-planar with butterfly conformation in the ground state, which can impede the molecular aggregation and the formation of molecular excimers. The additional electron rich sulfur atom renders phenothiazine a strong donor than other amines, even better than tetrahydroquinoline and carbazole. ${ }^{6-8}$

Meanwhile the 10-substitution of $\mathrm{N}$ can further enhance the charge separation at the oxide solution surface. Moreover, the two phenyl groups are arranged in a small torsion angle related to $\mathrm{N}(10)$ and $\mathrm{S}$ (9) atoms, so that $\pi$-delocalization can be extended over the entire chromophores. In addition, the electronic properties and the structural diversity can be enhanced by the attachments of auxiliary chromophores to the amine unit. ${ }^{9-13}$ Fine - tuning of the frontier molecular orbital energies are required to achieve efficient electron injection from the dye into the conduction band of $\mathrm{TiO}_{2}$ and facile regeneration of the oxidized dyes by a redox couple. Likewise, organic dyes with D-D- $\pi$-A structure can achieve the enhanced photovoltaic performance via the modification of molecular structure compared with $\mathrm{D}-\pi$-A structure. $^{14-19}$
Introducing an imidazole derivative as an additional donor to the $\mathrm{D}-\pi$-A structure is a possible alternative to retard the interfacial charge recombination dynamics and to retain efficient light-induced charge separation and lead to extend $\pi$-conjugation of the chromophores. ${ }^{20,21}$ Therefore, taking all the above mentioned points in to consideration, we designed and developed D-D- $\pi$-A structured metal free organic dyes consisting of phenothiazine as donor and $\pi$-spacerla, an imidazole derivative as additional donor and different electron withdrawing anchoring groups (cyanoacetic acid, ${ }^{22}$ nitrophenyl acetonitrile ${ }^{23-26}$ and rhodanine acetic $\mathrm{acid}^{27}$ ). The newly synthesized dyes are characterized by NMR and FT-IR spectral analysis. Further, their absorption, emission and electrochemical behavior were carefully analyzed. The molecular structure of the three dyes, namely SS PI1, SS PI2 and SS PI3 are displayed in Figure 1.

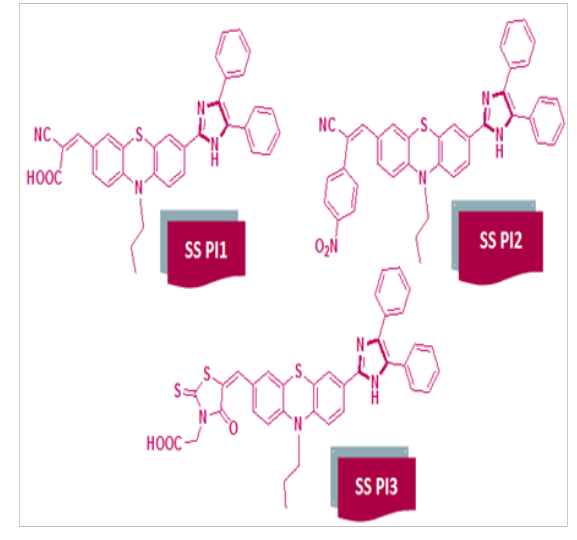

Figure I Molecular structure of the synthesized dyes. 


\section{Experimental part}

\section{Synthetic procedures}

General procedure for the synthesis of 10-propyl-10H-phenothiazine (S1); N - alkylation: A dimethyl sulfoxide (DMSO) solution of phenothiazine (2) $(0.5 \mathrm{mmol})$ was allowed to stirred for $30 \mathrm{~min}$. with sodium hydroxide $(\mathrm{NaOH})(0.1 \mathrm{~mol})$ at room temperature. To this, propyl bromide $(0.5 \mathrm{mmol})$ was added drop wise and the mixture was stirred at room temperature for 17 hours. The mixture was quenched with water and extracted with ethyl acetate (EtOAc), washed with water, dried in vacuum and the compound was purified by column chromatography (silica gel 60-120 mesh, hexane/EtOAc) $(5: 0.5 \mathrm{v} / \mathrm{v})$ as an eluent to afford the compound (S1) as a white solid.

Yield: $85 \%,{ }^{1} \mathrm{H}$ NMR $\left(400 \mathrm{MHz}, \mathrm{CDCl}_{3}, \mathrm{ppm}\right): \delta \mathrm{H} 1.0(\mathrm{t}, 3 \mathrm{H}, 7.6$ $\mathrm{Hz}), 1.8(\mathrm{~m}, 2 \mathrm{H}), 3.8(\mathrm{t}, 2 \mathrm{H}, 7.2 \mathrm{~Hz}), 6.8-6.9(\mathrm{~m}, 4 \mathrm{H}), 7.1(\mathrm{~m}, 4 \mathrm{H})$, ${ }^{13} \mathrm{C}$ NMR (400MHz, $\mathrm{CDCl}_{3}$, ppm): $\delta$ 145.36, 127.45, 127.19, 124.96, 124.35, 115.45, 49.15, 20.19,11.39, IR (KBr Pellet, $\left.\mathrm{cm}^{-1}\right)$ : 3461, 2967 , 2856, 1907, 1675, 1587, 1462, 1127,1026, 831

General procedure for the synthesis of 10-propyl-10h-phenothiazine-3,7-dicarbaldehyde (S2) ; vilsmeier - haack formylation: A mixture of DMF $(0.1 \mathrm{~mol})$ and $\mathrm{POCl}_{3}(4 \mathrm{mmol})$ in $2 \mathrm{ml}$ of 1, 2-dichloroethane (DCE) were allowed to cool for $0^{\circ} \mathrm{C}$ and stirred for $30 \mathrm{~min}$. To this, phenothiazine $(2)(0.4 \mathrm{mmol})$ in DCE $(3 \mathrm{ml})$ was added and the mixture was stirred at $100^{\circ} \mathrm{C}$ for 8 hours. The mixture was quenched with ice cooled water and filtered, washed with water, dried in vacuum and the compound was purified by column chromatography (silica gel 60-120 mesh, hexane/EtOAc) $(5: 1 \mathrm{v} / \mathrm{v})$ as an eluent to afford the compound (S2) as a orange solid.

Yield: $76 \%,{ }^{1} \mathrm{H}$ NMR $\left(400 \mathrm{MHz}, \mathrm{CDCl}_{3}, \mathrm{ppm}\right): \delta \mathrm{H} 1.0(\mathrm{t}, 3 \mathrm{H}, 8.4$ $\mathrm{Hz}), 1.8(\mathrm{~m}, 2 \mathrm{H}), 3.8$ - 3.9 (t, 2H, $7.6 \mathrm{~Hz}), 6.9$ (m, 2H), $7.5-7.6(\mathrm{~m}$, $4 \mathrm{H}), 9.8(\mathrm{~s}, 2 \mathrm{H}),{ }^{13} \mathrm{C} \mathrm{NMR}\left(400 \mathrm{MHz}, \mathrm{CDCl}_{3}, \mathrm{ppm}\right): \delta 189.89,148.90$, 131.99, 130.18, 128.41, 124.42, 115.62, 50.19, 29.99,11.12, IR ( $\mathrm{KBr}$ Pellet, cm-1): 3424, 2961, 2602, 1670, 1487, 1353, 1201, 1104, 914.

General procedure for the synthesis of 7-(4,5-diphenyl-1H-imidazol-2-yl)-10-propyl-10H-phenothiazine-3-carbaldehyde (S3); cyclocondensation: Acetic acid solution of 1, 2-diphenylethane-1,2-dione $(0.5 \mathrm{mmol})$, compound S2 $(0.05 \mathrm{mmol})$ and ammonium acetate $(8.07 \mathrm{mmol})$ were charged sequentially in a double necked round bottom flask and allowed to reflux at $105^{\circ} \mathrm{C}$ for 18 hours. The mixture was quenched with ice and filtered, washed with water, dried in vacuum and the compound was purified by column chromatography (silica gel 60-120 mesh, dichloromethane/EtOAc) (50:1 v/v) as an eluent to afford the compound (S3) as a yellowish orange solid.

Yield: $62 \%$, mp: $154-156^{\circ} \mathrm{C},{ }^{1} \mathrm{H}$ NMR $(400 \mathrm{MHz}, \mathrm{DMSO} \mathrm{d} 6, \mathrm{ppm})$ : $\delta \mathrm{H} 1.0(\mathrm{t}, 3 \mathrm{H}, 7.6 \mathrm{~Hz}), 1.8(\mathrm{~m}, 2 \mathrm{H}), 4.0(\mathrm{t}, 2 \mathrm{H}, 7.2 \mathrm{~Hz}), 7.3-7.7(\mathrm{~m}$, 16H), $9.8(\mathrm{~s}, 1 \mathrm{H}), 12.6(\mathrm{~s}, 1 \mathrm{H})$, IR $\left(\mathrm{KBr}\right.$ Pellet, $\left.\mathrm{cm}^{-1}\right): 3428,3037$, $2954,1650,1467,1367,1176,769$

General procedure for the synthesis of SS PI1, SS PI2 and SS PI3; knoevenagel condensation: $\mathrm{A} \mathrm{CHCl}_{3}$ solution of $\mathrm{P} 2(0.1 \mathrm{mmol}$, $0.2 \mathrm{mmol}$ and $0.5 \mathrm{mmol}$ with respect to SS PI1, SS PI2 and SS PI3) and cyanoacetic acid $(0.2 \mathrm{mmol}$ for SS PI1), 4-nitrophenylacetonitrile $(0.2$ mmol for SS PI2) and rhodanine-3-acetic acid (0.6 mmol for SS PI3) ( $2 \mathrm{mmol}$ ) with $0.1 \mathrm{ml}$ of piperidine were allowed to reflux at $70^{\circ} \mathrm{C}$ for 4hours.

The reaction mixture was extracted with $\mathrm{CHCl}_{3}$ and filtered, washed with water, dried in vacuum and the compound was purified by column chromatography (silica gel 60-120 mesh, dichloromethane/ ethanol) $(6: 1 \mathrm{v} / \mathrm{v})$ as a eluent to afford the title compounds SS PI1, SS PI2 and SS PI3 as deep yellow solid, brownish red solid and pale red solid respectively.

2-Cyano-3-[7-(4,5-diphenyl-1H-imidazol-2-yl)-10-propyl-10H-phenothiazin-3-yl]-acrylic acid; (SS PI1): Yield: 48\%, mp: 258$260^{\circ} \mathrm{C},{ }^{1} \mathrm{H}$ NMR $\left(400 \mathrm{MHz}, \mathrm{CDCl}_{3}, \mathrm{ppm}\right): \delta \mathrm{H} 1.8$ (t, 3H, $\left.5.2 \mathrm{~Hz}\right), 3.2$ $(\mathrm{m}, 2 \mathrm{H}), 3.4(\mathrm{t}, 2 \mathrm{H}, 6.0 \mathrm{~Hz}), 6.8(\mathrm{~s}, 1 \mathrm{H}), 7.3-7.4(\mathrm{~m}, 6 \mathrm{H}), 7.5-7.6$ $(\mathrm{m}, 10 \mathrm{H}), 8.0(\mathrm{~s}, 1 \mathrm{H})$, IR (KBr Pellet, $\left.\mathrm{cm}^{-1}\right): 3421,2951,2834,2235$, $16224,1461,1350,1252,946,771$

3 - [ 7 - (4,5-diphenyl- 1 H-imidazol-2-yl)- 10 -propy l- $10 \mathrm{H}$ phenothiazin-3-yl]-2-(4-nitro-phenyl)-acrylonitrile; (SS PI2): Yield: $62 \%$, mp: $230-232^{\circ} \mathrm{C},{ }^{1} \mathrm{H}$ NMR $\left(400 \mathrm{MHz}, \mathrm{CDCl}_{3}, \mathrm{ppm}\right): \delta \mathrm{H}$ 1.8 (t, 3H, $22 \mathrm{~Hz}), 3.7$ (m, 2H), 3.9 (t, 2H, $7.2 \mathrm{~Hz})$,

5-[7-(4,5-diphenyl-1H-imidazol-2-yl)-10-propyl-10H-phenothiazin-3-ylmethylene]-4-oxo-2-thioxo-thiazolidin-3-yl\}-acetic acid; (SS PI3): Yield: $54 \%$, mp: $168-170^{\circ} \mathrm{C},{ }^{1} \mathrm{H} \mathrm{NMR}\left(400 \mathrm{MHz}, \mathrm{CDCl}_{3}\right.$, ppm): $\delta \mathrm{H} 1.8(\mathrm{t}, 3 \mathrm{H}, 34 \mathrm{~Hz}), 3.3(\mathrm{~m}, 2 \mathrm{H}), 3.5$ (t, 2H, $9.2 \mathrm{~Hz}), 6.8$ (s, $1 \mathrm{H}), 6.9-7.0(\mathrm{~m}, 2 \mathrm{H}), 7.3-7.4(\mathrm{~m}, 3 \mathrm{H}), 7.4(\mathrm{~m}, 3 \mathrm{H}), 7.4-7.8(\mathrm{~m}, 8 \mathrm{H}$, ) $7.6(\mathrm{~s}, 1 \mathrm{H}), \mathrm{IR}\left(\mathrm{KBr}\right.$ Pellet, $\left.\mathrm{cm}^{-1}\right): 3412,2937,2832,2722,2523$, 1641, 1471, 1373, 1192, 1106, 1015, 690.

\section{Results and discussion}

\section{Synthesis and characterization}

The synthesis of three new imidazole - phenothiazine based donor - donor $-\pi$-acceptor dyes are accomplish as shown in Figure 2. The structures of the synthesized dyes (coded as SS P11, SS PI2 and SS PI3) are given in Figure 1.

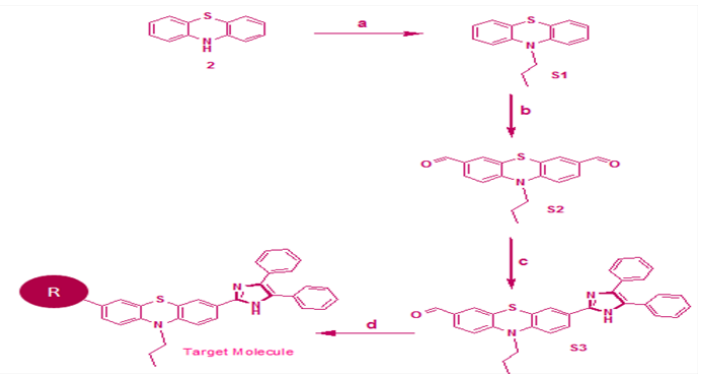

SS PII ( $R=$ Cyanoacetic acid), SS PI2 ( $R=4-$ Nitrophenyl acetonitrile), SS PI3 ( $R=$ Rhodanine-3- acetic acid).

Figure 2 (A) Propyl bromide, $\mathrm{NaOH}$, DMSO. (B) Phosphorous oxychloride, N,N- Dimethylformamide, I,2 -Dichloroethane, reflux $90^{\circ} \mathrm{C}, 12 \mathrm{hr}$. (C) Benzil, Ammonium acetate, Acetic acid, reflux $105^{\circ} \mathrm{C}, 28 \mathrm{hr}$. (D) Active Methylene Compound, Chloroform, Piperidine, reflux $105^{\circ} \mathrm{C}, 4 \mathrm{hr}$.

The synthetic pathways for the dyes involved stepwise protocol. First, the compounds S1 and S2 were prepared according to the reported procedure ${ }^{6,7 b}$ from compound 2 based on $\mathrm{N}$-alkylation and Vilsmeier - Haack formylation, respectively. Then, 1, 2 -diphenylethane-1, 2-dione reacts with S2 and ammonium acetate in the acetic acid, which gave the corresponding compound S3 via cyclocondensation reaction.

Finally, the compound S3 with two fold excess of active methylene compounds (Cyanoacetic acid, Nitrophenyl acetonitrile and Rhodanine acetic acid) afforded the target dyes (SS PI1, SS PI2 and SS PI3) in chloroform with piperidine as catalyst using Knoevenagel 
condensation reaction. The structure of intermediates and the dye molecules were characterized by ${ }^{1} \mathrm{HNMR},{ }^{13} \mathrm{CNMR}$ and FT-IR spectroscopic techniques (included in appendix II). The difference in the three dyes is majorly related to the acceptor part, which has variation in electron withdrawing nature, where the anchoring of $\mathrm{TiO}_{2}$ occurs.

\section{Optical properties}

Generally, as the function of light harvesting, the dye plays a significant role for the DSC's achieving high conversion efficiency and the absorption spectra of the dye could affect the device performance dramatically. ${ }^{20}$ Figure 3. shows the UV/Visible absorption spectra of the synthesized dyes SS PI1, SS PI2 and SS PI3 in dichloromethane solution and the corresponding data are summarized in Table 1. All dyes exhibited two distinct bands, appearing below $400 \mathrm{~nm}$ and around 400-510 nm respectively. The band located at a shorter wavelength (band 1) is attributed to an aromatic $\pi-\pi^{*}$ transition, and the band at a longer wavelength (band 2) is assigned to an intramolecular charge transfer (ICT) transition with the character of $\pi-\pi^{*}$ transition from the phenothiazine donor consisting of auxiliary chromophores to the electron withdrawing anchoring group..$^{28-30}$

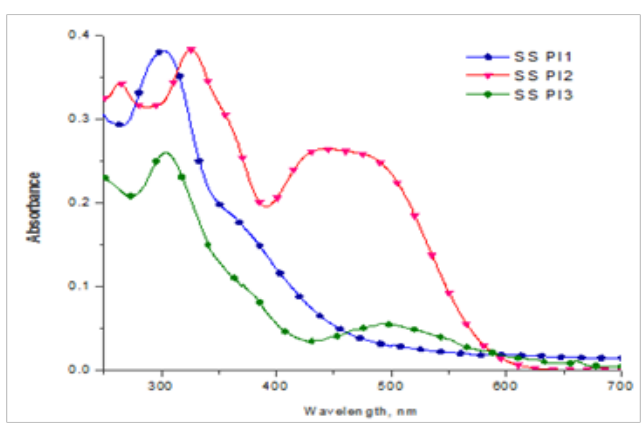

Figure 3 Absorption spectra of the synthesized dyes in $\mathrm{CH} 2 \mathrm{Cl}$.

Table I Absorption, photoluminescence, electrochemical data and HOMO, LUMO energy levels of the synthesized dye

\begin{tabular}{|c|c|c|c|c|c|c|}
\hline Dyes & $\begin{array}{l}\lambda_{\text {abs }} / \mathbf{n m} \\
(\varepsilon / \\
\left.M^{-1} \mathbf{c m}^{-1}\right)^{\mathrm{a}}\end{array}$ & $\begin{array}{l}\lambda_{\mathrm{em}} \\
(\mathbf{n m})^{b}\end{array}$ & $\begin{array}{l}\mathbf{E}_{\text {номо }} \\
(\mathbf{V})^{\mathbf{c}}\end{array}$ & $\begin{array}{l}E_{\text {LUMO }} \\
(V)^{\mathbf{d}}\end{array}$ & $E_{g}(e V)^{e}$ & $E O x / V^{f}$ \\
\hline \multirow[t]{2}{*}{ SS PI1 } & $302, * 402$ & 478 & 5.69 & -2.88 & 2.81 & 1.29 \\
\hline & 38,090 & & & & & \\
\hline \multirow[t]{2}{*}{ SS PI2 } & 325,466 & 495 & 5.65 & -3.26 & 2.39 & 1.25 \\
\hline & 38,200 & & & & & \\
\hline \multirow[t]{2}{*}{ SS PI3 } & 305,503 & 523 & 5.75 & -3.48 & 2.27 & 1. 35 \\
\hline & 25,980 & & & & & \\
\hline
\end{tabular}

aAbsorption spectra was measured in Dichloromethane solutions (IXI0-5M) at $\mathrm{rt}$, *weak absorption band

bPhotoluminescence spectra is measured in N,N-Dimethylformamide solutions (IXI0-6M)

c,d EHOMO and ELUMO were calculated from the oxidation potential of the dyes and $\mathrm{Eg}$

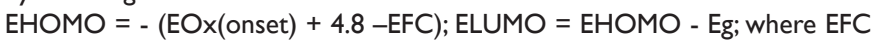
is potential of internal standard ferrocene.

fOxidation potential of the synthesized dyes (ImM) were obtained from cyclic voltammetry with $0.1 \mathrm{M}$ n-TBAPF6 as supporting electrolyte (scanning rate, $300 \mathrm{mV} / \mathrm{s}$; working electrode and counter electrode, $\mathrm{Pt}$ electrode and $\mathrm{Pt}$ wire; reference electrode, $\mathrm{Ag} / \mathrm{AgCl}$ ) potentials measured vs $\mathrm{Ag} / \mathrm{AgCl}$ were converted $\mathrm{n}$ to $\mathrm{NHE}$ by addition of $0.2 \mathrm{~V}$

$\mathrm{eEg}$ was estimated from the onset of absorption and photoluminescence spectra of the synthesized dye.
The absorption band of SS PI2 and SS PI3 with nitrophenyl acetonitrile and rhodanine acetic acid as an acceptor exhibits red shift about $35 \mathrm{~nm}$, compared to that of SS PI1 with cyanoacetic acid anchoring part and this shift is owing to that the nitrophenyl acetonitrile and rhodanine acetic acid units extend the $\pi$ system of the ring via the nitrophenyl ring and 4-oxo-2-thioxothiazolidine ring. ${ }^{31}$ In comparison with SS PI2 and SS PI3, the molar extinction coefficient of SS PI1 is higher, which is an advantageous spectral property for light harvesting ability. However, the compound SS PI1 exhibits one strong absorption band in shorter wavelength and another one band in the visible region shows weak absorption band, because of the molecular structure of SS PI1 having lesser number of heteroatom as compared with SS PI2 and SS PI3. The two bands observed in the spectra is due to introducing imidazole derivative to the framework of phenothiazine core resulting of an improved light harvesting ability. ${ }^{32,33}$

Noticeably, the compounds SS PI1, SS PI2 and SSPI3 possess a broader absorption range (red shift) and higher molar extinction coefficients $\left(38,090 \mathrm{M}^{-1} \mathrm{~cm}^{-1}, 38,200 \mathrm{M}^{-1} \mathrm{~cm}^{-1}\right.$ and $25,980 \mathrm{M}^{-1} \mathrm{~cm}^{-}$ ${ }^{1}$ ), which should be favorable for photocurrent generation in DSC's because more photons can be harvested. ${ }^{1 a}$ Moreover, these molar extinction coefficients $(\varepsilon)$ of the dyes are high compared with promising organometallic ruthenium dyes such as N3 $\left(13900 \mathrm{M}^{-1} \mathrm{~cm}-\right.$ $\left.{ }^{1}\right)$ and N719 $\left(14000 \mathrm{M}^{-1} \mathrm{~cm}^{-1}\right)$.

The absorption spectra of dyes anchored on nanocrystalline $\mathrm{TiO}_{2}$ film are displayed in Figure 4. Though the absorption tailing for the dyes in dichloromethane solution is quite similar, it moved towards high energy in photoanode. Generally the dyes form aggregates at the surface of the $\mathrm{TiO}_{2}$. A red shift is witnessed when J-aggregates are predominant and the dye- $\mathrm{TiO}_{2}$ interaction is weak. ${ }^{34}$ On the contrary the formation of $\mathrm{H}$ aggregates at the $\mathrm{TiO}_{2}$ surface or stronger dye$\mathrm{TiO}_{2}$ interactions causes a blue shift in the absorption profile. ${ }^{35,36}$ Noticeable wider and red shift for the synthesized dyes may be ascribed to the predominant dye- $\mathrm{TiO}_{2}$ interactions (deprotonation of carboxylic acid), as the substituted imidazole unit present in the donor part of the dye will inhibit the close intermolecular association of dyes at the surface of $\mathrm{TiO}_{2}$ better than the N-propyl chain. However, the longer alkyl chains could decrease the unfavorable aggregation on the $\mathrm{TiO}_{2}$ surface, ${ }^{37,38}$ which has been suggested accountable for greater DSC's performances.

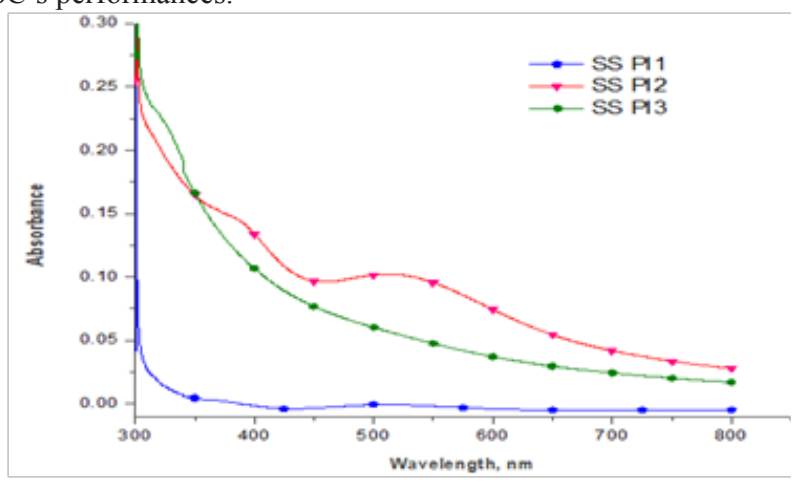

Figure 4 Absorption spectra of TiO2 films sensitized by SS PII, SS PI2 and SS PI3.

The emission spectra of the dyes recorded in dichloromethane solutions (Figure 5) are in similar in nature and the effect of peripheral units is not significant. This suggests that this excited state is ICT nature. Based on the intersection of absorption and emission spectra, the zeroth - zeroth transition energies $\left(\mathrm{E}_{0}-\mathrm{E}_{0}\right)$ of the dyes SS PI1, SS 
PI2 and SS PI3 are estimated to be $2.81,2.39$ and $2.75 \mathrm{eV}$, respectively.

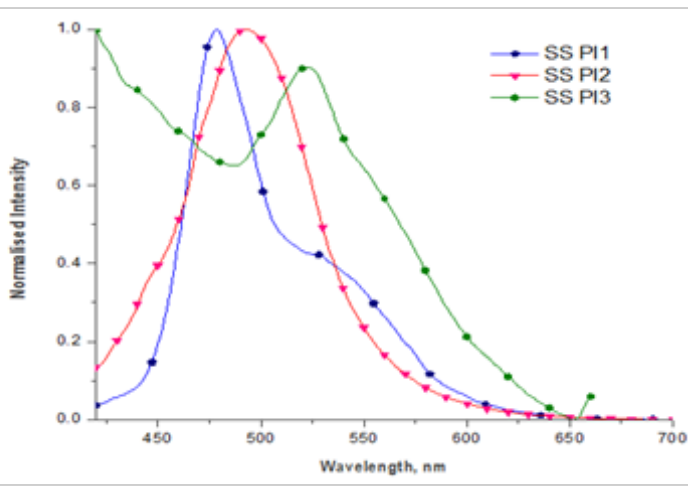

Figure 5 Photoluminescence spectra of the synthesized dyes in $\mathrm{CH} 2 \mathrm{Cl} 2$.

\section{Electrochemical behavior}

To evaluate the thermodynamic possibility of electron injection and sensitizer regeneration, cyclic voltamograms (Figure 6) recorded in $\mathrm{N}, \mathrm{N}$, - dimethyl formamide to determine the oxidation potentials (Table 1). The oxidation potential $\left(\mathrm{E}_{\mathrm{ox}}\right)$ correspond to HOMOs. as listed in Table 1., the HOMO level of dyes SS PI1, SS PI2 and SS PI3 were 5.69 V, 5.65 V and 5.75 V vs NHE respectively; these values are more negative than the $\mathrm{I} \mathrm{I}^{-} / \mathrm{I}_{3}^{-}$redox potential value $(0.4 \mathrm{~V}$ vs $\mathrm{NHE})$, indicating that the oxidized dyes could be efficiently regenerated by the electrolyte.

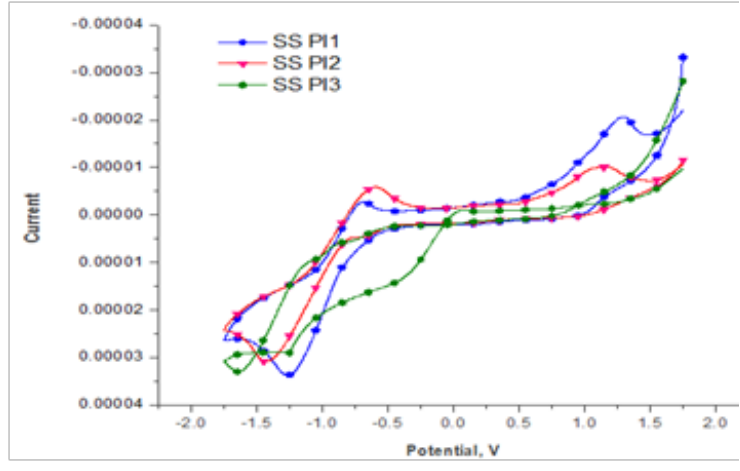

Figure 6 Cyclic voltamograms of the synthesized dyes dissolved in DMF with scan rate of $100 \mathrm{mV} / \mathrm{sec} . \mathrm{Vs} \mathrm{Ag} / \mathrm{AgCl}$.

The resulting $\mathrm{E}_{0-0}$ values were estimated from the onset of absorption and emission spectra of these dyes. The LUMOs were calculated from the values of $\mathrm{E}_{\mathrm{ox}}$ and the zero-zero band gaps $\left(\mathrm{E}_{0-0}\right)$. As a result, the LUMO levels of dyes SS PI1, SS PI2 and SS PI3 are -2.88 $\mathrm{V},-3.26 \mathrm{~V}$ and $-3.48 \mathrm{~V}$ respectively, which are more negative than the conduction band (CB) edge of $\mathrm{TiO}_{2}(-0.5 \mathrm{~V}$ vs NHE), providing the thermodynamic feasibility of electron injection from the excited dye molecules into the $\mathrm{CB}$ of $\mathrm{TiO}_{2}$. According to a report in the literature, stronger electron donating ability of the donor group results in a higher HOMO energy level. ${ }^{27}$

The schematic energy levels of the dyes based on absorption and electrochemical data are shown in Figure 7. According to Figure 7 these dyes are considered to have proper electronic energy levels as promising sensitizers in DSC's.

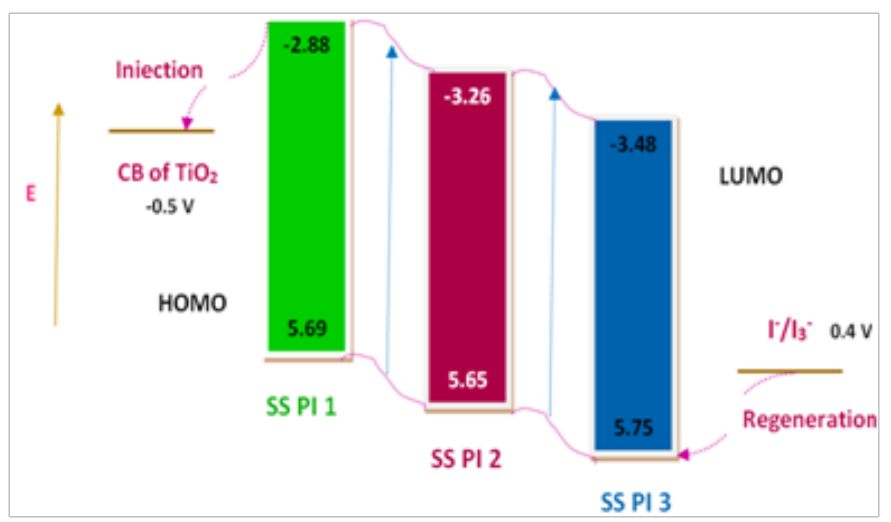

Figure 7 Schematic energy levels of synthesized dyes based on optical and electrochemical data.

\section{Conclusion}

In this work, we have designed and developed a new imidazole -phenothiazine based organic dyes namely SS PI1, S PI2 and SS PI3 and characterized by NMR and FT -IR spectroscopic analyses. Their optical and electrochemical properties were studied systematically. From the obtained results, we found that the auxiliary chromophores imidazole derivative plays an important role in light harvesting ability of the dyes via its extended $\pi$-conjugation. Likewise, the cyanoacetic acid acceptor moiety has unique structural features as compared with the other two anchoring units we used which have higher molar extinction coefficient and efficient binding ability on $\mathrm{TiO}_{2}$ surface. Based on the literature reports these phenothiazine core based dyes can achieve above $5 \%$ efficiency and this contribution will pave a new way for further molecular design of sensitizers for efficient DSC's.

\section{Acknowledgements}

S.S. thanks to University Grants Commission (UGC), Government of India for financial support through the UGB BSR fellowship (Ref. No. F. 4-1/2006 (BSR)/ 7-22/2007 (BSR) Dt. 26 June, 2012), Department of Science and Technology (DST), Science and Engineering Research Board (SERB), Government of India for International Travel Support (SB/ITS-Y/04782/2014-15, Dt. 30.12.2014) and Department of Science and Technology (DST), Fund for Improvement of S\&T Infrastructure (FIST) for sanctioning DST FIST Program 2017 level '0' (SR/FST/College - 111/2017; Dt. 16.01.2018).

\section{Conflict of interest}

The authors declare no competing financial interest.

\section{References}

1. Nazeeruddin MK, Péchy P, Grätzel M. Efficient panchromatic sensitization of nanocrystalline $\mathrm{TiO}_{2}$ films by a black dye based on atrithiocyanatoruthenium complex. Chem Comm. 1997;(18):1705-1706.

2. Mishra A, Fisher MK, Bäuerle P. Metal-free organic dyes for dye-sensitized solar cells: from structure: property relationships to design rules. Angew Chem Int Engl. 2009;48(14):2474-2499.

3. Chen $\mathrm{S}, \mathrm{Xu} \mathrm{XJ}$, Liu YQ, et al. Synthesis and Characterization of $\mathrm{n} \square$ Type Materials for Non $\square$ Doped Organic Red $\square$ Light $\square$ Emitting Diodes. Adv Funct Mater. 2005;15(9):1541-1546. 
4. Tsai YL, Chang CC, Kang CC, et al. Effect of different electronic properties on 9-aryl-substituted BMVC derivatives for new fluorescence probes. $J$ Lumin. 2007;127(1):41-47.

5. Yoon KR, Ko SO, Lee SM, et al. Synthesis and characterization of carbazole derived nonlinear optical dyes. Dyes and Pigments. 2007;75(3):567-573.

6. Roquet S, Cravino A, Leriche P, et al. Triphenylamine-Thienylenevinylene Hybrid Systems with Internal Charge Transfer as Donor Materials for Heterojunction Solar Cells. J Am Chem Soc. 2006;128(10):3459-3466.

7. Marszalek M, Nagane S, Ichake A, et al. Tuning spectral properties of phenothiazine based donor- $\pi$-acceptor dyes for efficient dye-sensitized solar cells. J Mater Chem. 2012;22(3):889-894.

8. Velusamy M, Hsu YC, Lin JT, et al. 1-Alkyl-1H-imidazole-based dipolar organic compounds for dye-sensitized solar cells. Chem Asian J. 2010;5(1):87-96.

9. Hara k, Sayama k, Ohga Y, et al. Chem Commun. 2009;2198.

10. Liang $\mathrm{M}, \mathrm{Wu} \mathrm{W}$, Cai F, et al. New Triphenylamine-Based Organic Dyes for Efficient Dye-Sensitized Solar Cells. J Phys Chem C. 2007;111(11):4465-4472.

11. Koumura N, Wang ZS, Miyashita M, et al. Substituted carbazole dyes for efficient molecular photovoltaics: long electron lifetime and high open circuit voltage performance. J Mater Chem. 2009;19(27):4829-4836.

12. Tian $\mathrm{H}$, Yang $\mathrm{X}$, Chen $\mathrm{R}$, et al. Phenothiazine derivatives for efficien organic dye-sensitized solar cells. Chem Commun. 2007;(36):3741-3743.

13. Wu W, Yang J, Hua J, et al. Efficient and stable dye-sensitized solar cells based on phenothiazine sensitizers with thiophene units. J Mater Chem. 2010;20(9):1772-1779.

14. Horiuchi T, Miura H, Sumioka $\mathrm{K}$, et al. High efficiency of dyesensitized solar cells based on metal-free indoline dyes. J Am Chem Soc 2004;126(39):12218-12219.

15. Horiuchi T, Miura H, Uchida S. Highly-efficient metal-free organic dyes for dye-sensitized solar cells. Chem Commun. 2003;(24):3036-3037.

16. Satoh N, Nakashima T, Yamamoto K. Metal-Assembling Dendrimers with a Triarylamine Core and Their Application to a Dye-Sensitized Solar Cell. J Am Chem Soc. 2005;127(37):13030-13038.

17. Ning Z, Tian H. Triarylamine: a promising core unit for efficien photovoltaic materials. Chem Commun. 2009;(37):5483-5495.

18. Tang J, Hua J, Wu W, et al. New starburst sensitizer with carbazole antennas for efficient and stable dye-sensitized solar cells. Energy Environ Sci. 2010;3(11):1736-1745.

19. Teng C, Yang X, Li S, et al. Tuning the HOMO Energy Levels of Organic Dyes for Dye $\square$ Sensitized Solar Cells Based on $\mathrm{Br}^{-} / \mathrm{Br}_{3}^{-}$Electrolytes. Chem Eur J. 2010;16(44):13127-13138.

20. Nagarajan N, Vanitha G, Ananth DA, et al. Bioimaging, antibacterial and antifungal properties of imidazole-pyridine fluorophores: synthesis, characterization and solvatochromism. $J$ Photochem Photobiol $B$ 2013;127:212-222.

21. Zhou L, Jia $\mathrm{C}$, Wan $\mathrm{Z}$, et al. Effect of imidazole derivatives in triphenylamine-based organic dyes for dye-sensitized solar cells. Organic Electronics. 2013;14(7):1755-1762.

22. Chen C, Liao JY, Chi Z, et al. Metal-free organic dyes derived from triphenylethylene for dye-sensitized solar cells: tuning of the performance by phenothiazine and carbazole. J Mater Chem. 2012;22(18):8994-9005.
23. Mao J, He N, Ning Z, et al. Angew Chem Int Ed. 2012;57;987.

24. Cong J, Yang X, Liu J, et al. Nitro group as a new anchoring group for organic dyes in dye-sensitized solar cells. Chem Commun. 2012;48(53):6663-6665.

25. Yang CH, Lin WC, Wang TL, et al. Mater Chem Phys. 2011;130:635.

26. Venkateswararao A, Justin Thomas KR, Lee CP, et al. Organic Dyes Containing Carbazole as Donor and $\pi$-Linker: Optical, Electrochemical, and Photovoltaic Properties. ACS App Mater Interfaces. 2014;6(4):2528 2539.

27. Vijay Kumar C, Raptis D, Koukaras EN, et al. Study of an indolinephenothiazine based organic dye for Dye-Sensitized Solar Cells. Theoretical calculations and experimental data. Organic Electronics. 2015;25:66-73.

28. Sirimanne PM, Tributsch H. Parameters determining efficiency and degradation of $\mathrm{TiO}_{2} \mid$ dye $\mid \mathrm{CuI}$ solar cells. J Solid State Chem. 2004;177(6):1789-1795.

29. Hsin $\mathrm{YC}$, Lung $\mathrm{CH}$, Yuan $\mathrm{CY}$, et al. Characteristics of triphenylaminebased dyes with multiple acceptors in application of dye-sensitized solar cells. J Power Sources. 2009;188(2):627-634.

30. Wan Z, Jia C, Duan Y, et al. Effects of different acceptors in phenothiazinetriphenylamine dyes on the optical, electrochemical, and photovoltaic properties. Dyes and Pigments. 2012;94(1):150-155.

31. Baheti A, Lee CH, Thomas KRJ, et al. Pyrene-based organic dyes with thiophene containing $\pi$-linkers for dye-sensitized solar cells: optical, electrochemical and theoretical investigations. Phys Chem Chem Phys. 2011;13(38):17210-17221.

32. Guo K, Yan K, Lu X, et al. Dithiafulvenyl Unit as a New Donor for HighEfficiency Dye-Sensitized Solar Cells: Synthesis and Demonstration of a Family of Metal-Free Organic Sensitizers. Org Lett. 2012;14(9):2214-2217.

33. Roquet $\mathrm{S}$, Cravino A, Leriche $\mathrm{P}$, et al. Triphenylamine-Thienylenevinylene Hybrid Systems with Internal Charge Transfer as Donor Materials for Heterojunction Solar Cells. J Am Chem Soc. 2006;128(10):3459-3466.

34. Xu W, Peng B, Chen J, et al. New Triphenylamine-Based Dyes for DyeSensitized Solar Cells. J Phys Chem C. 2008;112(3):874-880.

35. Paramaguru G, Aravindkumar C, Peng G, et al. Molecular Engineering of 2-Quinolinone Based Anchoring Groups for Dye-Sensitized Solar Cells. $J$ Phys Chem C. 2014;118(30):16896-16903.

36. Baheti A, Singh P, Lee CP, et al. 2,7-Diaminofluorene-Based Organic Dyes for Dye-Sensitized Solar Cells: Effect of Auxiliary Donor on Optical and Electrochemical Properties. J Org Chem. 2011;76(12):4910-4920.

37. Liang $\mathrm{M}, \mathrm{Xu} \mathrm{W}$, Cai F, et al. New Triphenylamine-Based Organic Dyes for Efficient Dye-Sensitized Solar Cells. J Phys Chem C. 2007;111(11):4465-4472.

38. Shi J, Chai Z, Su J, et al. New sensitizers bearing quinoxaline moieties as an auxiliary acceptor for dye-sensitized solar cells. Dyes and Pigments. 2013;98(3):405-413. 